\title{
COMUNICAÇÃO
}

\section{SELEÇÃO DE BACTÉRIAS ENDOFÍTICAS DE TOMATEIRO COMO POTENCIAIS AGENTES DE BIOCONTROLE E DE PROMOÇÃO DE CRESCIMENTO ${ }^{1}$}

\author{
Screening of endophytic bacteria isolated from tomato plants as \\ potencial biocontrol agents and growth promotion
}

Patrícia Baston Barretti ${ }^{2}$, Reginaldo da Silva Romeiro ${ }^{3}$, Eduardo Seiti Gomide Mizubuti ${ }^{3}$, Jorge Teodoro de Souza ${ }^{4}$

\begin{abstract}
RESUMO
Quarenta isolados bacterianos endofíticos de plantas sadias de tomateiro foram avaliados quanto à sua potencialidade como agentes de biocontrole de doenças do tomateiro. Foi realizada, em casa de vegetação, uma seleção massal utilizando-se Pseudomonas syringae pv. tomato e Alternaria solani, como patógenos desafiantes. Com base na média do número de lesões por planta, quatro isolados foram selecionados como potenciais agentes de biocontrole dessas enfermidades fúngica e bacteriana do tomateiro. Esses isolados foram identificados, por meio do sequenciamento do gene 16S do DNA ribossômico, como Acinetobacter johnsonii (UFVE05), Serratia marcescens (UFV-E13), Sinorhizobium sp. (UFV-E25) e Bacillus megaterium (UFV-E26). Os mesmos isolados selecionados para o biocontrole também foram avaliados quanto à sua capacidade de promover o crescimento em plantas e somente S. marcescens (UFV-E13) proporcionou aumento na altura das plantas.
\end{abstract}

Termos para indexação: Endófitas, antagonistas, Lycopersicon esculentum, pinta preta, mancha bacteriana pequena.

\begin{abstract}
Forty isolates of endophytic bacteria obtained from healthy tomato plants were tested for their potential as biocontrol agents of tomato diseases. A massal screening was performed at greenhouse using Pseudomonas syringae pv. tomato and Alternaria solani as challenging pathogens. Based on the average number of lesions per plant, four isolates were selected as potential agents of biocontrol of these tomato diseases caused by fungi and bacteria. These isolates were identified by $16 \mathrm{~S}$ ribosomal DNA sequence analysis as Acinetobacter johnsonii (UFV-E05), Serratia marcescens (UFV-E13), Sinorhizobium sp. (UFV-E25) and Bacillus megaterium (UFV-E26). The four endophytes selected for biocontrol were also evaluated for their ability of promoting plant growth and only S. marcescens (UFV-E13) presented increase in the height of the plants.
\end{abstract}

Index terms: Endophytes, antagonists, Lycopersicon esculentum, early blight, bacterial speck.

(Recebido em 17 de abril de 2007 e aprovado em 3 de junho de 2008)

Desde 1940, as pesquisas relatam a presença de bactérias endofíticas em órgãos distintos de uma ampla gama de plantas herbáceas ou arbóreas, cultivadas ou não (HALLMANN et al., 1997; STURZ et al., 2000). Os primeiros relatos as consideravam contaminantes resultantes da desinfestação superficial incompleta ou patógenos fracamente virulentos (HOLLIS, 1951; THOMAS \& GRAHAM, 1952). Porém, pesquisas mais recentes demonstraram que as bactérias endofíticas são habitantes naturais do interior das plantas e podem reduzir os sintomas causados por diversos fitopatógenos e promover o crescimento de seus hospedeiros (CHEN et al., 1995; FROMMEL et al., 1991; PEER \& SCHIPPERS, 1989; PLEBAN et al., 1995).

Considerando como alvo as doenças fúngicas, as bactérias endofíticas mostraram-se eficientes agentes de biocontrole em patossistemas como Fusarium oxysporum f. sp. vasinfectum (CHEN et al., 1995) e Rhizoctonia solani (PLEBAN et al., 1995) em algodão; Sclerotium rolfsii em feijão (PLEBAN et al., 1995); Pythium myriotylum, R. solani,

\footnotetext{
${ }^{1}$ Parte da dissertação apresentada à Universidade Federal de Viçosa/UFV, Viçosa, MG, pela primeira autora para obtenção do título de Mestre em Fitopatologia

${ }^{2}$ Engenheira Agrônoma, Doutora em Fitopatologia - Departamento de Fitopatologia/DFP - Universidade Federal de Lavras/UFLA - 37200-000 - Lavras, MG patriciabaston@hotmail.com

${ }^{3}$ Engenheiros Agrônomos, PhD em Fitopatologia - Departamento de Fitopatologia/DFP - Universidade Federal de Viçosa/UFV - $36570-000$ - Viçosa, MG rromeiro@ufv.br; mizubuti@ufv.br

${ }^{4}$ Engenheiro Agrônomo, PhD em Fitopatologia - Centro de Ciências Agrárias, Ambientais e Biológicas/CCAAB - Universidade Federal do Recôncavo da Bahia/UFRB - 44380-000 - Cruz das Almas, BA - jorgetdes@yahoo.com.br
} 
Gaeumannomyces graminis e Heterobasidium annosum em arroz (MUKHOPADHYAY et al., 1996), entre outros. Com relação às doenças bacterianas, as bactérias endofíticas foram eficientes como agentes de biocontrole de Xanthomonas campestris pv. oryzae em arroz (POON et al., 1977); Clavibacter michiganensis subsp. sepedonicus (BUREN et al., 1993) e Erwinia carotovora var. atroseptica (STURZ \& MATHESON, 1996) em batata e X. campestris pv. campestris em repolho (ASSIS et al., 1998).

Os efeitos benéficos das bactérias endofíticas em plantas são variáveis. Nas últimas décadas, estudos mostraram que além de controlar doenças, elas também são capazes de promover o crescimento de plantas. Vários relatos indicam que bactérias endofíticas já foram associadas à promoção de crescimento em diversas culturas, incluindo plantas de batata (FROMMEL et al., 1991), alface, tomate, pepino (PEER \& SCHIPPERS, 1989), milho, arroz e algodão (HALLMANN et al., 1997). De acordo com Sturz (1995), aproximadamente 10\% das bactérias endofíticas isoladas de tubérculos de batata promoveram o crescimento das plantas. De maneira semelhante, Silva (2004) observou que plantas de tomateiro tratadas com as bactérias endofíticas Acinetobacter johnsonii e Bacillus pumilus tiveram incrementos de $9,5 \%$ e $20,2 \%$ na altura, respectivamente. Durante a seleção de 150 isolados de bactérias endofíticas com potencial para controlar a murcha bacteriana, Barretti et al. (2008) observaram que 53 isolados agiram como promotores de crescimento de plantas de tomateiro, sendo que o isolado UFV-E49 promoveu o maior crescimento, cujos aumentos na altura, área foliar, número de folhas, peso da matéria fresca e seca da parte aérea, peso da matéria fresca e seca das raízes foram, respectivamente, $23,40 \%, 105,80 \%, 19,53 \%, 42,40 \%$, $61,64 \%, 100 \%$ e $225 \%$ maiores do que a testemunha. Tais resultados tornam este grupo de microrganismos como potenciais candidatos a promotores de crescimento.

Dessa forma, objetivou-se, no presente trabalho, isolar e selecionar bactérias endofíticas como potenciais agentes de biocontrole da mancha bacteriana pequena $\mathrm{e}$ da pinta preta e avaliar o efeito desses isolados sobre o crescimento de plantas de tomateiro.

As bactérias foram cultivadas em meio 523 de Kado \& Heskett (1970) e preservadas por dois métodos: repicagem tubo a tubo (KIRALY et al., 1970; TUITE, 1969) e sob óleo mineral (LELLIOT \& STEAD, 1987). O fungo foi cultivado em meio BDA (TUITE, 1969) e preservado por meio de repicagens tubo a tubo, mensalmente.

Plantas sadias de tomateiro, apresentando idades variadas e nunca antes expostas a fertilizantes químicos ou a agrotóxicos, foram coletadas em hortas orgânicas da região de Viçosa, MG.
Pequenos fragmentos de folhas e caules foram lavados em água de torneira e enxugados em papel absorvente. Em seguida, a superfície foi desinfestada com álcool $50 \%$, por 1 minuto, hipoclorito de sódio $2 \%$, por 6 minutos, e lavada em água destilada esterilizada, por três vezes. Os fragmentos do tecido foram triturados em água destilada e esterilizada e o triturado obtido permaneceu em repouso por 15 minutos, para que houvesse difusão das bactérias para a solução (ROMEIRO, 2001). Após esse período, as suspensões bacterianas obtidas foram semeadas, pelo método de estrias, em placas que continham o meio 523 e incubadas a $28{ }^{\circ} \mathrm{C}$. Todas as colônias bacterianas desenvolvidas foram repicadas para tubos de ensaio, contendo o meio 523.

Para ter mais segurança quanto ao isolamento de bactérias endofíticas, utilizou-se uma contraprova. A metodologia empregada foi a descrita por Assis et al. (1998), com algumas modificações. $\mathrm{O}$ fragmento de planta, após a terceira lavagem em água destilada esterilizada, foi seccionado em duas partes. Uma delas foi triturada, conforme já descrito. A outra foi imersa em tubo de ensaio, contendo o meio 523 líquido, e imediatamente descartada. O tubo de ensaio também foi incubado a $28{ }^{\circ} \mathrm{C}$ e observado, a fim de comprovar a ausência de crescimento de organismos epifíticos. Não havendo crescimento bacteriano nesses tubos de ensaio, os isolados obtidos pela maceração dos tecidos foram considerados endofíticos.

Foi utilizada a metodologia do corte do hipocótilo, descrita por Kijima et al. (1995). Plântulas de tomateiro da cultivar Santa Clara, apresentando o segundo par de folhas definitivas, foram seccionadas na região do hipocótilo, utilizando-se lâmina de barbear. O sistema radicular foi descartado e o restante da planta imerso, por 6 horas, em suspensão de células de cada bactéria endofítica, ajustada em espectrofotômetro para $\mathrm{DO}_{540}=0,2$ (BARRETTI et al., 2001). As plantas utilizadas como testemunha foram processadas da mesma forma, mas imersas em água destilada e esterilizada. Posteriormente, em casa de vegetação, as seções de parte aérea foram plantadas em solo esterilizado, aguardando-se o enraizamento.

Foram eleitas duas doenças, uma bacteriana (mancha bacteriana pequena) e outra fúngica (pinta preta), causadas respectivamente por Pseudomonas syringae pv. tomato (Okabe) Young, Dye \& Wilkie e Alternaria solani Sorauer. Quinze dias após a dispensa dos antagonistas, os patógenos desafiantes foram inoculados artificialmente, com um atomizador manual, sendo o inóculo de $P$. syringae pv. tomato previamente ajustado para $\mathrm{DO}_{540}=0,1$ e de $A$. solani para $2 \times 10^{3}$ conídios $/ \mathrm{mL}$. A testemunha também foi atomizada com os patógenos desafiantes. As plantas foram 
mantidas em câmara úmida por 24 horas antes e após a inoculação. Posteriormente, foram transferidas para casa de vegetação, onde permaneceram até o término do ensaio. $\mathrm{O}$ delineamento experimental foi o inteiramente casualizado, com 41 tratamentos e dez repetições, sendo cada planta considerada uma unidade experimental. Os tratamentos foram constituídos por 40 isolados endofíticos e uma testemunha tratada com água destilada esterilizada (testemunha absoluta).

Quando surgiram os sintomas típicos das doenças, 10 e 11 dias após a inoculação com $P$. syringae pv. tomato e A. solani, respectivamente, procedeu-se à contagem do número de lesões por planta.

Para avaliar a capacidade de promoção de crescimento dos isolados selecionados para biocontrole, quinze dias após a dispensa dos antagonistas, mediu-se a altura das plantas, tomando a distância do ponto de inserção das folhas cotiledonares até o ápice da folha mais alta. $\mathrm{O}$ delineamento experimental utilizado foi o inteiramente casualizado, com cinco tratamentos e 10 repetições, sendo cada planta considerada uma unidade experimental. Os tratamentos foram constituídos por quatro isolados endofíticos e uma testemunha tratada com água destilada esterilizada (testemunha absoluta).

Os dados de altura das plantas de tomate foram submetidos à análise de variância pelo teste $\mathrm{F}$ e, quando significativo, as médias dos tratamentos foram comparadas pelo teste de Fisher LSD, ao nível de 5\% de probabilidade.

Os antagonistas com melhor desempenho como agentes de biocontrole foram identificados pelo seqüenciamento do gene $16 \mathrm{~S}$ do RNA ribossômico. O DNA genômico foi extraído pelo método do CTAB modificado (SOUZA et al., 2003). O gene 16S rDNA foi amplificado via PCR, utilizando-se os primers 8fn (5'-AGA GTT TGA TCC TGG CTC AG-3') e 1429r (5'- ACG GCT ACC DTT GTT ACG ACT T- 3') (ESIKOVA et al., 2002). As reações de PCR foram feitas conforme Souza et al. (2003). Os produtos amplificados foram separados em géis de agarose de acordo com métodos descritos por Sambrook \& Russel (2001). O seqüenciamento direto foi efetuado através de um kit contendo terminadores marcados com fluorescência em um seqüenciador de DNA automático modelo ABI 3100, de acordo com as recomendações do fabricante (Applied Biosystems do Brasil, São Paulo, SP). As seqüências foram montadas no programa Sequencing Analysis, versão 5.1.1 (Applied Biosystems do Brasil). Alinhamentos das seqüências obtidas foram feitos com o programa CLUSTAL W, versão 1.8; e buscas, com o programa BLASTN, foram efetuadas nos bancos de dados públicos. As seqüências dos genes foram depositadas no GenBank e receberam os seguintes números de acesso: EF114343 (UFV-E05), EF114344 (UFV-E13), EF114345 (UFV-E25) e EF114346 (UFV-E26).
Ao todo foram obtidos 40 isolados de bactérias endofíticas a partir das folhas e caules de plantas de tomateiro, sem sintomas de doenças. Esses isolados apresentaram grande variação quanto à cor, à forma e à velocidade de crescimento.

Os isolados deste trabalho foram obtidos conforme técnica usual preconizada para isolamento a partir de órgão vegetais infectados (ROMEIRO, 2001), mas aumentandose a exposição ao hipoclorito de sódio para seis minutos. Além disso, visando à retirada de toda a microbiota epifítica porventura remanescente após a desinfestação superficial, outra etapa foi acrescentada ao processo. De fato, a contraprova foi utilizada com sucesso para isolamento de endofíticas, permitindo descartar os isolados de bactérias epifíticas e/ou residentes de filoplano.

Independente da técnica utilizada no isolamento, encontram-se na literatura relatos de vários autores que também isolaram bactérias endofíticas de diversas partes de plantas de diferentes culturas, entre elas batata, tomate, pepino, algodão, milho (HALLMANN et al., 1997), ervilha, feijão, melão, banana, repolho, pimentão e trigo (STURZ et al., 2000).

As plantas de tomateiro inoculadas artificialmente com $P$. syringae pv. tomato e $A$. solani foram avaliadas aos 10 e 11 dias após a inoculação, respectivamente, estimandose a média do número de lesões por planta (NLP) (Tabela 1). O NLP obtido para cada isolado endofítico variou em função do patógeno inoculado. Assim, observou-se que a porcentagem de controle variou de $10,71 \%$ a $69,94 \%$ para $P$. syringae pv. tomato e de $4,35 \%$ a $60,87 \%$ para $A$. solani. No entanto, nem todos os isolados eficazes para $P$. syringae pv. tomato mostraram o mesmo desempenho para A. solani. Dessa forma, tornou-se necessária a análise do desvio-padrão de cada um dos isolados de bactérias endofíticas submetidos à seleção massal. Com base nesses resultados, quatro isolados foram escolhidos como possíveis agentes de controle biológico da mancha bacteriana pequena e da pinta preta do tomateiro: UFV-E05, UFV-E13, UFV-E25 e UFV-E26.

Resultados promissores de controle biológico foram obtidos por Chen et al. (1995), os quais mostraram que, de 170 isolados endofíticos, 40 possuíam atividade de biocontrole contra Rhizoctonia solani, em algodão. Da mesma forma, Brooks et al. (1994) selecionaram isolados antagônicos a Ceratocystis fagacearum, agente causal da murcha do carvalho, conseguindo uma redução de $39 \%$ de plantas doentes em condições de casa de vegetação.

Assis et al. (1998), utilizando as bactérias endofíticas Kluyvera ascorbata e Alcaligenes piechaudii para o controle da podridão negra em repolho (Xanthomonas campestris pv. campestris), obtiveram de $40 \%$ a $70 \%$ de redução da incidência e de $60 \%$ a $80 \%$ de redução da severidade da doença, em casa de vegetação e campo, respectivamente. 
Tabela 1 - Número médio de lesões por planta (NLP) e desvio-padrão (s) em plantas de tomateiro tratadas com bactérias endofíticas e inoculadas com Pseudomonas syringae pv. tomato ou Alternaria solani.

\begin{tabular}{|c|c|c|c|c|c|c|}
\hline \multirow[t]{2}{*}{ Tratamento } & \multicolumn{3}{|c|}{$\begin{array}{c}\text { Mancha bacteriana pequena } \\
\text { (Pseudomonas syringae pv. tomato) }\end{array}$} & \multicolumn{3}{|c|}{$\begin{array}{c}\text { Pinta preta } \\
\text { (Alternaria solani) }\end{array}$} \\
\hline & NLP & $\%$ controle & $\mathrm{s}$ & NLP & $\%$ controle & $\mathrm{s}$ \\
\hline UFV-E02 & $4,1^{1}$ & $26,79^{2}$ & 1,4 & $3,0^{1}$ & - & 0,7 \\
\hline UFV-E05 & 2,2 & 60,71 & 0,6 & 1,5 & $34,78^{2}$ & 1,0 \\
\hline UFV-E06 & 5,9 & - & 2,0 & 2,6 & - & 1,8 \\
\hline UFV-E10 & 3,5 & 37,50 & 1,5 & 3,7 & - & 1,9 \\
\hline UFV-E13 & 3,6 & 35,71 & 1,2 & 1,2 & 47,83 & 0,3 \\
\hline UFV-E14 & 3,2 & 42,86 & 1,2 & 2,0 & 13,04 & 0,6 \\
\hline UFV-E15 & 4,8 & 14,29 & 0,4 & 2,2 & 4,35 & 0,9 \\
\hline UFV-E17 & 4,3 & 23,21 & 1,1 & 2,0 & 13,04 & 0,4 \\
\hline UFV-E18 & 4,2 & 25,00 & 1,1 & 1,5 & 34,78 & 0,3 \\
\hline UFV-E21 & 6,1 & - & 3,7 & 2,0 & 13,04 & 0,9 \\
\hline UFV-E22 & 3,6 & 35,71 & 1,6 & 2,7 & - & 1,5 \\
\hline UFV-E23 & 2,7 & 51,78 & 0,8 & 3,0 & - & 1,8 \\
\hline UFV-E24 & 3,6 & 35,71 & 8,7 & 1,7 & 26,09 & 1,0 \\
\hline UFV-E25 & 3,8 & 32,14 & 0,7 & 1,5 & 34,78 & 0,4 \\
\hline UFV-E26 & 3,0 & 46,43 & 0,9 & 1,7 & 26,09 & 0,4 \\
\hline UFV-E27 & 3,9 & 30,56 & 1,1 & 2,4 & - & 1,5 \\
\hline UFV-E28 & 4,1 & 26,79 & 1,3 & 0,9 & 60,87 & 0,3 \\
\hline UFV-E29 & 9,6 & - & 4,5 & 2,0 & 13,04 & 0,8 \\
\hline UFV-E30 & 2,9 & 48,21 & 0,7 & 2,8 & - & 1,7 \\
\hline UFV-E31 & 4,5 & 19,64 & 3,4 & 2,3 & - & 0,7 \\
\hline UFV-E32 & 5,7 & - & 0,8 & 3,8 & - & 2,8 \\
\hline UFV-E33 & 8,9 & - & 3,0 & 1,1 & 52,17 & 0,7 \\
\hline UFV-E34 & 6,0 & - & 2,7 & 2,8 & - & 1,7 \\
\hline UFV-E35 & 8,9 & - & 3,0 & 1,5 & 34,78 & 0,5 \\
\hline UFV-E36 & 5,8 & - & 3,0 & 4,2 & - & 1,2 \\
\hline UFV-E37 & 5,6 & - & 1,0 & 4,7 & - & 0,7 \\
\hline UFV-E39 & 4,5 & 19,64 & 1,0 & 2,3 & - & 0,5 \\
\hline UFV-E40 & 3,8 & 32,14 & 1,0 & 4,7 & - & 1,6 \\
\hline UFV-E41 & 6,2 & - & 2,7 & 1,9 & 17,39 & 1,1 \\
\hline UFV-E42 & 7,0 & - & 1,4 & 3,1 & - & 1,6 \\
\hline UFV-E43 & 5,8 & - & 1,7 & 4,0 & - & 1,3 \\
\hline UFV-E45 & 5,0 & 10,71 & 2,1 & 3,8 & - & 0,5 \\
\hline UFV-E48 & 1,7 & 69,64 & 1,7 & 2,7 & - & 1,3 \\
\hline UFV-E49 & 8,9 & - & 4,1 & 3,6 & - & 0,8 \\
\hline UFV-E51 & 4,4 & 21,43 & 1,0 & 3,1 & - & 1,0 \\
\hline UFV-E52 & 4,2 & 25,00 & 1,6 & 3,8 & - & 1,5 \\
\hline UFV-E53 & 6,1 & - & 1,0 & 4,3 & - & 3,3 \\
\hline UFV-E54 & 3,8 & 32,14 & 0,7 & 3,3 & - & 1,5 \\
\hline UFV-E56 & 4,1 & 26,79 & 1,6 & 1,6 & 30,43 & 1,0 \\
\hline UFV-E57 & 6,1 & - & 1,0 & 3,0 & - & 0,7 \\
\hline Testemunha & 5,6 & - & 2,0 & 2,3 & - & 0,9 \\
\hline
\end{tabular}

${ }^{1}$ Média do número de lesões por plantas; ${ }^{2 \%}$ de controle da doença em relação à testemunha.

De acordo com Silva et al. (2008), 53 isolados de bactérias endofíticas de tomateiro e pimentão foram testados contra a mancha bacteriana pequena, em casa- de-vegetação. Para o desenvolvimento desse experimento, sementes de tomateiro foram microbiolizadas em suspensão de célula de cada 
antagonista, e em seguida plantadas. Posteriormente, as plantas foram inoculadas com a bactéria desafiante. Os autores constataram que nove isolados foram eficientes no controle da doença.

Em experimentos desenvolvidos com bactérias endofíticas no controle de fitonematóides, em casa de vegetação, Naves et al. (2004) avaliaram o antagonismo de 40 isolados à formação de galhas e à reprodução de Meloidogyne javanica em tomateiro. Todos os isolados testados diferiram da testemunha quanto ao número de galhas por grama de raiz, apresentando porcentuais de redução que variaram entre 18,79 e 58,68\%. Quanto ao número de ovos por grama de raiz, apenas três isolados não diferiram da testemunha. Para os demais isolados, foram observadas reduções significativas entre 20,75 e $64,87 \%$ para esse parâmetro.

Dentre as quatro bactérias endofíticas selecionadas como possíveis agentes de biocontrole somente o isolado UFV-E13 diferiu estatisticamente do tratamento controle no tocante à promoção de crescimento de plantas de tomateiro, proporcionando aumento de $15,16 \%$ na altura das plantas tratadas. O isolado UFV-E26 mostrou efeito de promoção de crescimento (aumento de $2,45 \%$ na altura), porém não diferiu da testemunha. Os isolados UFV-E25 e UFV-E05 não demonstraram características eficientes de promoção de crescimento (Figura 1).

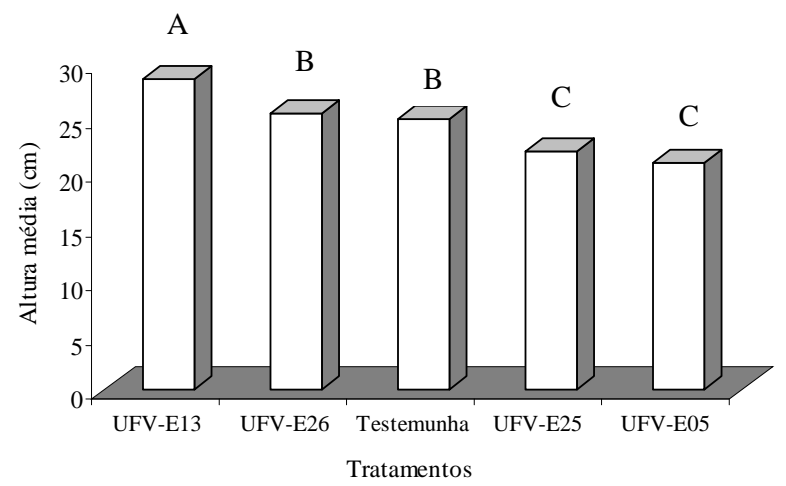

Figura 1 - Altura média de plantas de tomateiro tratadas com bactérias endofíticas. Colunas com a mesma letra não diferem entre si pelo teste de Fisher LSD, a 5\% de probabilidade.

Neste trabalho foram avaliados altura, peso de matéria fresca (PMF) e peso de matéria seca (PMS). Os dados de PMF e PMS não apresentaram diferença significativa (dados não mostrados). Porém, a altura apresentou resultado significativo, o que é um indicativo de promoção de crescimento. Entretanto, reconhecemos a limitação de ter usado apenas um parâmetro na avaliação de promoção de crescimento.

A maioria dos programas de controle biológico empregando microrganismos visa, além da capacidade de controlar doenças, a capacidade desses microrganismos atuarem também como promotores de crescimento. Obviamente, o que se deseja é que o microrganismo apresente as duas características simultaneamente. Porém, segundo Oberhänsli et al. (1991) são raros os casos em que um isolado bacteriano apresenta, ao mesmo tempo, características de biocontrole e de promoção de crescimento.

Para a identificação dos isolados selecionados, as sequiências obtidas foram comparadas com seqüências já existentes nos bancos de dados públicos. Um fragmento de $1.410 \mathrm{pb}$ do gene 16S rDNA foi obtido para o isolado UFV-E05. Essa seqüência apresentou 100\% de identidade, quando comparada à sequiência desse gene para o isolado CAI-6 de Acinetobacter johnsonii, o qual é encontrado nos bancos de dados públicos sob o número de acesso DQ257426 e 99,9\% de identidade quando comparada à sequiência do isolado CAI-27 de A. johnsonii, encontrado sob o número de acesso DQ257430. O fragmento de 1.439 pb, obtido para o isolado UFV-E13, assemelhou-se mais, apresentando $99,8 \%$ de identidade, quando comparado com as seqüências dos isolados 615 e 6CW de Serratia marcescens, encontrados nos bancos de dados sob os números AJ550467 e DQ417332, respectivamente. O fragmento de $1.297 \mathrm{pb}$ seqüenciado para o isolado UFVE25 foi muito semelhante e apresentou 99,9\% de identidade, quando comparado com seqüências do gene 16S rDNA dos isolados HI-B13, J1 e BK1 de Sinorhizobium sp., encontradas nos bancos de dados sob os números de acesso DQ196475, DQ294628 e AJ012210, respectivamente. Para o isolado UFV-E26, foi sequienciado um fragmento de $1.455 \mathrm{pb}$, o qual foi mais próximo (99,9\% de identidade) quando comparado com sequiências do gene 16S rDNA dos isolados 2-37-4-1, AC46B1, MO31 e MPF-906 de Bacillus megaterium encontradas nos bancos de dados sob os números de acesso DQ267829, AJ717381, AY553118 e DQ660362, respectivamente.

Considerando-se a semelhança entre as seqüências dos isolados estudados e as seqüências encontradas nos bancos de dados, o isolado UFV-E05 foi identificado como Acinetobacter johnsonii, o isolado UFV-E13 como Serratia marcescens, UFV-E25 como Sinorhizobium sp. e o isolado UFV-E26 como Bacillus megaterium. 
Segundo Hallmann et al. (1997) e Sturz et al. (2000), aproximadamente 129 espécies de bactérias endofíticas, representando 54 gêneros já foram isoladas. Dentre elas, B. megaterium, S. marcescens e espécies do gênero Acinetobacter (STURZ, 1995; STURZ et al., 1997), conforme pode ser observado nesse trabalho.

As bactérias A. johnsonii, Sinorhizobium sp. e $S$. marcescens apresentaram-se como bastonetes Gramnegativos e B. megaterium como bastonete Gram-positivo. Exceto para $S$. marcescens, cujas colônias apresentaram pigmentação, as demais apresentaram coloração branca a creme e nenhuma produziu pigmentos fluorescentes. $A$. johnsonii e Sinorhizobium sp. são aeróbicas estritas enquanto $S$. marcescens e $B$. megaterium são anaeróbicas facultativas (HOLT et al., 1994).

Muitos microrganismos encontrados em associação com plantas podem ser patogênicos a seres humanos, como é o caso de $S$. marcescens que é um patógeno oportunista, causando septicemia e infecções no trato urinário (HOLT et al., 1994).

Os resultados obtidos nesta pesquisa mostraram que algumas bactérias endofíticas atuaram no controle da mancha bacteriana pequena e da pinta preta e também na promoção de crescimento de plantas de tomateiro. No entanto, nem sempre um mesmo isolado apresenta, ao mesmo tempo, características de biocontrole e de promoção de crescimento.

\section{AGRADECIMENTOS}

À CAPES, pela concessão da bolsa de estudos, ao CNPq e à FAPEMIG, pelo apoio financeiro.

\section{REFERÊNCIAS BIBLIOGRÁFICAS}

ASSIS, S. M. P.; SILVEIRA, E. B.; MARIANO, R. L. R.; MENEZES, D. Bactérias endofíticas: método de isolamento e potencial antagônico no controle da podridão negra em repolho. Summa Phytopathologica, Jaboticabal, v. 24, p. 216-220, 1998.

BARRETTI, P. B.; SOUZA, R. M. de; POZZA, E. A. Bactérias endofíticas como agentes promotores do crescimento de plantas de tomateiro e de inibição in vitro de Ralstonia solanacearum. Ciência e

Agrotecnologia, Lavras, v. 32, n. 3, p. 731-739, maio/jun., 2008.

BARRETTI, P. B.; ROMEIRO, R. S.; MIZUBUTI, E. S. G. Isolamento e seleção de bactérias endofíticas de tomateiro como potenciais agentes de biocontrole. In: CONGRESSO BRASILEIRO DE FITOPATOLOGIA, 34.,
2001, São Pedro. Anais... São Pedro: SBF, 2001. p. 274275.

BROOKS, D. S.; GONZALEZ, C. F.; APPEL, D. N.; FILER, T. H. Evaluation of endophytic bacteria as potential biological control agents for oak wilt. Biological Control, San Diego, v. 4, p. 373-381, 1994.

BUREN, A. M. van; ANDRE, C.; ISHIMARU, C. A. Biological control of the bacterial ring rot pathogen by endophytic bacteria isolated from potato.

Phytopathology, Saint Paul, v. 83, p. 1406, 1993.

CHEN, C.; BAUSK, E. M.; MUSSON, G.; RODRÍGUEZKÁBANA, R.; KLOEPPER, J. W. Biological control of Fusarium wilt on cotton by use of endophytic bacteria. Biological Control, San Diego, v. 5, p. 83-91, 1995.

ESIKOVA, T. Z.; TEMIROV, Y. V.;SOKOLOV, S. L.; ALAKHOV, Y. B. Secondary antimicrobial metabolites produced by the thermophilic Bacillus strains VK2 and VK21. Applied Biochemistry and Microbiology, New York, v. 38, p. 226-231, 2002.

FROMMEL, M. I.; NOWAK, J.; LAZAROVITS, G. Growth enhancement and developmental modifications of in vitro grown potato (Solanum tuberosum ssp. tuberosum) as affected by a nonfluorescent Pseudomonas sp. Plant Physiology, Rockville, v. 96, p. 928-936, 1991.

HALLMANN, J.; QUADT-HALLMANN, A.; MAHAFFEE, W. F.; KLOEPPER, J. W. Bacterial endophytes in agricultural crops. Canadian Journal of Microbiology, Ottawa, v. 43, p. 895-914, 1997.

HOLLIS, J. P. Bacteria in healthy potato tissue. Phytopathology, Madison, v. 41, p. 350-367, 1951.

HOLT, J. C.; KRIEG, N. R.; SNEATH, P. H. A.; STALEY, J. T.; WILLIAMS, S. T. Bergey's manual of determinative bacteriology. 9. ed. Baltimore: Williams \& Wilkins, 1994. 787 p.

KADO, C. I.; HESKETT, M. G. Selective media for isolation of Agrobacterium, Corynebacterium, Erwinia, Pseudomonas and Xanthomonas. Phytopathology, Saint Paul, v. 60, p. 969-976, 1970.

KIJIMA, T.; YONAI, S.; OOHASHI, K.; AMAGAI, M. Process for biologically preventing dicotyledoneous plant diseases using symbiotical bacteria. USA Patent. No. 5.401.655 (03-28-1995). 1995. 12 p. 
KIRALY, Z.; KLEMENT, Z.; SOLIMOSY, F.; VOROS, J. Methods in plant pathology. Budapest: Akademiai Kiadó, 1970. 509 p.

LELLIOT, R. A.; STEAD, D. E. Methods for the diagnosis of bacterial plant diseases. Oxford: Blackwell Scientific, 1987. $216 \mathrm{p}$.

MUKHOPADHYAY, N. K.; GARRISON, N. K.; HINTON, D. M.; BACON, C. W.; KHUSH, G. S.; PECK, H. D.; DATTA, N. Identification and characterization of bacterial endophytes of rice. Mycopathologia, Dordrecht, v. 134, p. 151-159, 1996.

NAVES, R. L.; CAMPOS, V. P.; SOUZA, R. M. Filtrados de culturas bacterianas endofíticas na motilidade, mortalidade e eclosão de juvenis de segundo estádio de Meloidogyne javanica. Fitopatologia Brasileira, Brasília, v. 29, p. 384-388, 2004.

OBERHÄNSLI, T.; DÉFAGO, G.; HAAS, D. Indole-3acetic acid (IAA) synthesis in the biocontrol strain CHAO of Pseudomonas fluorescens: role of tryptophan side chain oxidase. Journal of General Microbiology, Oxford, v. 37, p. 2273-2279, 1991.

PEER, R. van; SCHIPPERS, B. Plant growth responses to bacterization with selected Pseudomonas spp. strains and rhizosphere microbial development in hydroponic cultures. Canadian Journal of Microbiology, Ottawa, v. 35, p. 456-463, 1989.

PLEBAN, S.; INGEL, F.; CHET, I. Control of Rhizoctonia solani and Sclerotium rolfsii in the greenhouse using endophytic Bacillus spp. European Journal of Plant Pathology, Dordrecht, v. 101, p. 665-672, 1995.

POON, E. S.; HUANG, T. C.; KUO, T. T. Possible mechanism of symptom inhibition of bacterial blight of rice by an endophytic bacterium isolated from rice. Botanical Bulletin of Academia Sinica, Taipei, v. 18, p. 61-70, 1977.

ROMEIRO, R. S. Métodos em bacteriologia de plantas. Viçosa: UFV, 2001. 279 p.

SAMBROOK, J.; RUSSELL, D. W. Molecular cloning: a laboratory manual. New York: Cold Spring Harbor Laboratory, 2001. 540 p.
SILVA, J. R. C. Bactérias endofíticas no controle da mancha (Xanthomonas vesicatoria) e da pinta bacterianas do tomateiro. 2004. 160 p. Dissertação (Mestrado em Fitopatologia) - Universidade Federal de Lavras, Lavras, 2004.

SILVA, J. R. C.; SOUZA, R. M.; ZACARONE, A. B.; SILVA, L. H. C. P.; CASTRO, A. M. S. Bactérias endofíticas no controle e inibição in vitro de Pseudomonas syringae pv tomato, agente da pinta bacteriana do tomateiro. Ciência e Agrotecnologia, Lavras, v. 32, n. 4, p. 1062-1072, jul./ago., 2008.

SOUZA, J. T.; MAZZOLA, M.; RAAIJMAKERS, J. M. Conservation of the response regulator gene gacA in Pseudomonas species. Environmental Microbiology, Washington, v. 5, p. 1328-1340, 2003.

STURTZ, A. V. The role of endophytic bacteria during seed piece decay and potato tuberization. Plant and Soil, Dordrecht, v. 175, p. 257-263, 1995.

STURZ, A. V.; CHRISTIE, B. R.; MATHESON, B. G.; NOWAK, J. Biodiversity of endophytic bacteria which colonize red clover nodules, roots, stems and foliage and their influence on host growth. Biology and Fertility of Soils, Berlim, v. 25, p. 13-19, 1997.

STURZ, A. V.; CHRISTIE, B. R.; NOWAK, J. Bacterial endophytes: potential role in developing sustainable systems of crop production. Critical

Reviews in Plant Sciences, Boca Raton, v. 19, p. 130, 2000.

STURZ, A. V.; MATHESON, B. G. Populations of endophytic bacteria which influence host-resistance to Erwinia-induced bacterial soft rot in potato tubers. Plant and Soil, Dordrecht, v. 184, p. 265-271, 1996.

THOMAS, W. D.; GRAHAM, R. W. Bacteria in apparently healthy pinto beans. Phytopathology, Madison, v. 42, p. 214, 1952.

TUITE, J. Plant pathological methods. Minneapolis: Burguess, 1969. 239 p. 